\title{
A CAUSALIDADE EM PEDRO DA FONSECA
}

António Manuel Martins*

RESUMO - Neste pequeno artigo pretendemos fazer uma primeira apresentação sumária da reflexão de Fonseca sobre as causas nos seus Comentários à Metafísica de Aristóteles. Começaremos pelo mapa das questões em torno da causalidade (I) para analisarmos, em seguida, a posição de Fonseca sobre a própria noção de causa (II), a relação entre princípio e causa (III) e a sua defesa do esquema causal quadripartido, a partir do texto de Aristóteles (IV).

PALAVRAS-CHAVE-Causa. Princípio. Explicação. Razão. Aristóteles. Fonseca.
ABSTRACT - In this paper we intend to present briefly the way Fonseca deals with the doctrine of causation in his Commentaries on the Metaphysics of Aristotle. We shall begin with the presentation of the map of the disputations on causation in that work (I), then will refer to the position of Fonseca on the definition of cause (II), the relation between cause and principle (III) and, finally, his defense of the Aristotelian four causes (IV).

KEY WORDS - Cause. Causation. Explanation. Justification. Aristotle. Fonseca.

\section{Introdução}

O que se segue mais não pretende do que introduzir e contextualizar, sumariamente, a reflexão de Pedro da Fonseca sobre as causas. Mas, antes de entrarmos na temática que nos ocupa convém relembrar algumas características formais da obra principal de Pedro da Fonseca. O texto dos Comentários à Metafísica de Aristóteles ${ }^{1}$ apresenta-se-nos com

* Universidade de Coimbra.

1 PEDRO da Fonseca. Commentariorvm... in libros metaphysicorvm Aristotelis... T. 1: Continet hic tomus quatuor primorum librorum explicationem.(Romae: Franciscus Zanettus, \& Bartholomaeus Tosius, 1577); T. 2: Continet hic tomus quinti libri explicationem (Romae: Jacobi Tornerii \& Franciscus Zanettus, 1589); T. 3: Continet hic tomus 6. 7. 8. et 9. lib. Explicationem (Eborae: E. de Lyra, 1604); T.4: in metaphysicorum Aristotelis Stagiritae decimum, undecimum, \& duodecimum: cum sequentium duorum interpretatione (Lugduni: $H$. Cardon, 1612). Estes quatro tomos foram reimpressos, a partir da edição de Colónia (1615-29), em dois volumes pela editora Olms (Hildesheim, 1964). Como os textos que se referem à causalidade se

\begin{tabular}{|l|l|l|l|l|l|}
\hline VERITAS & Porto Alegre & v. 54 & n. 3 & set./dez. 2009 & p. 112-127 \\
\hline
\end{tabular}


quatro níveis ou componentes principais dos quais os três primeiros estão centrados no texto aristotélico e o último, o das quaestiones, representa um esforço de sistematização de um pensamento metafísico em que Aristóteles é o autor de referência mas a amplitude da reflexão é muito mais vasta. Aqui é determinante a autocompreensão que Fonseca tem da Filosofia em geral e da Filosofia Primeira em particular. A presença do texto aristotélico continua a manifestar-se a cada passo mas deixou de ser a única fonte. Funciona sempre como um texto que foi, de facto, superado. As consequências não fazem recuar Fonseca na prossecução do seu projecto.

Reconhecendo ser imprescindível a familiaridade com a obra de Aristóteles sublinha que em Filosofia a procura do verdadeiro é o único critério fundamental aceitável:

Quanto ao resto, como pensamos que, tratando-se de questões filosóficas, não se deve jurar pela palavra de nenhum doutor, também não rejeitámos a opinião de nenhum filósofo menos conhecido quando nos pareceu mais consentânea com o verdadeiro; reconhecendo, plenamente, que a verdade, dita por quem quer que seja, dimana da verdade primeira. Nem seguimos as nossas opiniões de tal modo que não estejamos dispostos a seguir, agora, quem tiver melhor opinião. ${ }^{2}$

Não se trata, portanto, como muitas vezes se quer fazer crer, de uma opção cega por Aristóteles. Basta ler o prólogo em que justifica amplamente a sua escolha do texto do Estagirita sem nunca se apresentar como defensor de uma qualquer variedade de aristotelismo em estado quimicamente puro. Esta filosofia primeira considera-se a si mesma "rainha de todas as disciplinas humanas" e, por isso, "tem todo o direito de reclamar para si as causas das disciplinas subordinadas e de, adicionando os princípios próprios, as investigar cuidadosamente". ${ }^{3} \mathrm{O}$ facto de Fonseca inserir as quaestiones a seguir a determinado passo do texto da Metafísica de Aristóteles pode dar a impressão de que a sua reflexão sistemática está afectada por um elevado índice de contextualização filológica. Impressão esta que se pode agudizar pelo

encontram maioritariamente nos tomos 1 e 2 e nem todas as bibliotecas possuem a reimpressão da Olms, citarei a partir da edição de Frankfurt (1599) que está agora acessível na internet no sítio da Biblioteca Pública de Munique. Contudo, deve salientar-se que a edição de Colónia, no que diz respeito aos dois primeiros tomos, reproduz a edição de Frankfurt (1599) mantendo exactamente a mesma paginação (http://www.digital-collections.de/index.html?c=autoren_index\&l=en\&ab=Fons eca\%2C+Pedro+da). Citarei usando a sigla CMA, seguida da indicação do tomo e da coluna referindo, no texto, sempre que necessário, a referência ao texto de Aristóteles e o número da quaestio e respectiva sectio.

2 PEDRO da Fonseca. CMA I, Admonitio Lectoris/Advertência.

3 PEDRO da Fonseca. CMA I, Admonitio Lectoris/Advertência 
facto de o texto dos Comentários à Metafísica de Aristóteles ser muito longo e ter sido publicado em quatro tomos com um intervalo temporal de mais de trinta anos. ${ }^{4}$

Contudo, como alguns textos do primeiro tomo dos CMA mostram, Fonseca tinha, desde a redacção dos primeiros textos da sua obra principal, uma visão bastante nítida da estrutura sistemática da sua metafísica e do lugar em que pretendia integrar cada um dos seus elementos. Isto aplica-se a todos os aspectos da sua metafísica e também à doutrina das causas. $\mathrm{E}$ deve ser tido em conta para entender a posição de Fonseca no seu preciso contexto histórico e estabelecer possíveis comparações com outros autores, designadamente aqueles que lhe estão mais próximos. O mapa de questões sobre a causalidade que a seguir propomos constitui um exercício preliminar de comparação entre dois textos muito próximos a variados títulos, o CMA de Fonseca e o primeiro tomo do Curso Conimbricense, dedicado à Física de Aristóteles. Ambos antecedem o célebre tratado de Suárez sobre as causas nas suas Disputationes Metaphysicae (1597) com o qual se iniciaria, nas palavras de Vincent Carraud, o "século da causalidade". 5

4 O primeiro tomo dos Comentários à Metafísica de Aristóteles sai, finalmente, em Roma, no segundo semestre de 1577, incluindo o texto, tradução, comentário de Met. I-IV e questões. O segundo volume dos Comentários à Metafísica de Aristóteles foi publicado, também em Roma, em 1589. O desenvolvimento das quaestiones em torno de Metafísica $\mathrm{V}$ assume tal proporção que o conjunto do texto associado a este léxico aristotélico acaba por ser ainda mais extenso que o primeiro volume publicado doze anos antes, também em Roma. O terceiro volume dos Comentários à Metafísica de Aristóteles será publicado, postumamente, em Évora, em 1604. Contudo, o texto deste volume estava já pronto em 1594 uma vez que existe correspondência dos anos 95 e 96 relativa à censura de algumas teses alegadamente menos ortodoxas. Fonseca tentou desvalorizar as críticas vindas de alguns sectores ligados a Coimbra e Évora bem como a Roma (Cf. ARSI, Lus., 72, fl. 213v, 216-7, 396; Lus. 73, fl. 162-3, fl. 215-215). Sem entrarmos em especulações infundadas talvez possamos compreender melhor alguma distância crítica relativamente a certas afirmações de Fonseca se nos lembrarmos que estava ainda muito viva a polémica desencadeada pela Concordia de Molina. Nas questões em que, no terceiro volume dos Comentários à Metafísica de Aristóteles, se analisam os atributos divinos Fonseca dificilmente poderia fugir a uma exposição e justificação da sua versão da scientia media ou ciência dos futuros condicionados. O quarto volume dos Comentários à Metafísica de Aristóteles só foi publicado em Lyon em 1612. Trata-se de um livro muito mais pequeno do que os restantes pois só inclui o texto e tradução dos livros X-XIV da Metafísica e a explanação dos livros X, XI e XII. Ficava, assim, incompleta a obra principal de Pedro da Fonseca. Sobre esta matéria ver o nosso estudo preliminar de 1991.

5 A monografia de CARRAUD (2002) visa a inscrever a fórmula cartesiana numa história do conceito de causalidade que teria um momento culminante na formulação do principio de razão suficiente (ou principium reddendae rationis) de Leibniz. Carraud faz anteceder a sua exposição da história do problema da causa, de Suarez a Leibniz, de um útil Vademecum onde sumaria os principais momentos da préhistória dos autores de que se ocupa (p. 7-102). A nossa leitura do texto de Fonseca não pressupõe a aceitação prévia de uma narrativa da história da metafísica que exclua outras grandes narrativas. 
A nossa análise é bem mais modesta e não tem qualquer ambição de contribuir para uma narrativa linear da história da filosofia. Muito pelo contrário.

O texto de Fonseca pode ser analisado de múltiplos ângulos: como intérprete (de Aristóteles e da tradição filosófica) e como pensador sistemático. Nem sempre é fácil separar estas dimensões e a doutrina das causas é um dos casos em que essa separação se torna mais problemática. Depois de uma brevíssima referência a um tópico da exegese do texto aristotélico em que Fonseca mostrou a sua originalidade como comentador de Aristóteles passaremos a uma apresentação sumária do mapa das questões em torno da causalidade (I) para analisarmos, em seguida, a posição de Fonseca sobre a própria noção de causa (II), a relação entre princípio e causa (III) e a sua defesa do esquema causal quadripartido, a partir do texto de Aristóteles (IV).

A causalidade do movente imóvel, tal como é apresentada no livro XII da Metafísica foi tradicionalmente interpretada em termos de causalidade final desde os comentadores antigos até ao século XX. A excepção mais conhecida era Brentano mas, muito antes dele, já Pedro da Fonseca tinha interpretado o texto de Aristóteles atribuindo, contra todos os intérpretes anteriores, a causalidade eficiente ao motor imóvel da teologia aristotélica. É um tema que não podemos aqui desenvolver mas que revela bem o facto de Fonseca não se limitar a repetir aquilo que outros disseram. Isto não quer dizer que ele não tenha assimilado muito das leituras que fez de autores seus contemporâneos e mais antigos desde os gregos passando pelos medievais que o invento de Gutenberg tornara acessíveis. Mas não só a nova tecnologia mas também um intenso labor sobre os textos. Os trabalhos de edição e comentário de Aristóteles, publicados no século XVI, continuam ainda desconhecidos da esmagadora maioria dos estudiosos da história da filosofia. Sobre esta questão concreta da interpretação da causalidade do motor imóvel remetemos o leitor interessado para as referências dadas por Enrico Berti em estudos recentes. ${ }^{6}$

6 Referindo-se à interpretação tradicional diz E. Berti: "Questa interpretazione è stata formulata per la prima volta, a nostra conoscenza, in maniera rigorosa, dal primo grande commentatore della Metafísica, Alessandro di Afrodisia, secondo il quale il Motore immobile sarebbe oggetto di amore da parte del cielo, e il cielo, essendo animato, si muoverebbe circolarmente allo scopo di imitare l'immobilità del motore immobile per mezzo del movimento che più le assomiglia, quello appunto circolare. Essa è stata ripresa, sia pure con alcune differenze, di tutti i commentatori sai antichi [...]. Sia infine rinascimentali, quali il padovano Iacopo Zabarella (con l'importante eccezione del gesuita Pedro da Fonseca". BERTI. 2005, p. 453. Depois de referir as tentativas infrutíferas de contrariar a interpretação dominante no século XX, feitas por Carlo Giacon - que invocava a autoridade de Fonseca a favor da sua interpretação - e de sublinhar que ele mesmo tinha defendido esta interpretação maioritária, na linha de David Ross e de toda a tradição, 
No plano original de Fonseca as questões da causalidade deveriam ser abordadas em três momentos distintos segundo a ordem e o tipo de análise desenvolvido no texto dos escritos de Aristóteles sobre a Metafísica. O primeiro momento corresponderia à análise desenvolvida por Aristóteles no livro I da Metafísica em que a preocupação pelo carácter exaustivo e completo do modelo de explicação causal é bem claro. O segundo está associado ao léxico apresentado no livro Delta (V) onde Fonseca desenvolve, ao longo de 18 quaestiones, o que poderíamos considerar o seu tratado mais sistemático sobre as causas. Finalmente, o terceiro estaria planeado para articular com o livro Lambda (XII) onde discutiria questões ligadas à natureza divina. Como sabemos Fonseca não chegou a acabar este texto do tomo $4 \mathrm{e}$, talvez porque tivesse tido a percepção de que já não conseguiria completar a sua obra, antecipou algumas dessas questões para o tomo 3, como se pode ver no mapa das questões (Quadro 1).

Aristóteles insiste em muitos aspectos nucleares da sua doutrina das categorias mas é-lhe relativamente indiferente saber se são exactamente dez ou não. Pelo contrário, relativamente ao seu modelo quadripartido da causalidade, todo o texto do livro I assenta no pressuposto de que o seu modelo é o mais completo e mais coerente. Por isso, é perfeitamente aceitável que Fonseca comece por esta questão, saber quantos são os tipos de causa (Quot sint causarum genera). Fonseca insere apenas outra quaestio sobre a causalidade neste primeiro tomo para discutir a tese aristotélica de que não pode haver séries causais infinitas (Num eiusdem rei dari possint infinitae causae). Esta primeira abordagem da problemática das causas (1577) é a mais familiar ao autor do texto do Curso Conimbricense (1592) que o cita repetidas vezes. Baste mencionar, a título de mero exemplo, o que ele diz a propósito da controvérsia sobre

Enrico Berti continua: "Solo nell'ultimo decennio del secolo sono apparsi alcuni studi intesi a riaprire il discorso, attribuendo al Motore immobile di Aristotele una causalità di tipo efficiente: in questo si sono segnalati autori come Sarah Broadie, Arieh Kosman, Lindsay Judson, ai quali mi sono affiancato anch'io in alcuni articoli recenti" (p. 454). No resto do artigo que estamos citando, Berti apresenta alguns elementos novos para apoiar esta interpretação que atribui ao motor imóvel uma causalidade de tipo eficiente. A interpretação continua sendo controversa. Mas o que não deixa de ser interessante é que tenha sido Fonseca o primeiro comentador a defender esta interpretação e que, nas últimas décadas haja um pouco mais de abertura para esta leitura e não seja tão prontamente silenciada como quando foi retomada por Brentano e por Giacon. Ver igualmente, de BERTI. 2000, p. 181-206, reimpresso em BERTI. 2005, p. 427-451. 
a causalidade exemplar remetendo para o texto de Fonseca, CMA I, c.7, q. 1, s. 5, "ubi totam hanc controuersiam accurate pertractat". ${ }^{7}$ Não deixa de ser curioso notar que Manuel de Góis dedique explicitamente duas quaestiones à querela sobre a causalidade exemplar enquanto Fonseca trata da questão no contexto mais amplo do número de causas. O mesmo se poderia dizer da questão da definição de causa. Fonseca trata essa questão na sua primeira análise, a seguir a Met. I, 7 embora retome a questão da diferença entre princípio e causa no tomo II, na q. 7, inserida a seguir a Delta 1. Quando redigiu o seu tratado sobre as causas, Manuel de Góis, muito provavelmente, não conhecia o texto de Fonseca (1589), publicado em Roma. Contudo, parece claro que foi feito um confronto, por sumário que tenha sido, com a reflexão sobre as causas desenvolvida em Fonseca (1589) como o indicam as referencias a este texto. ${ }^{8}$ As questões colocadas por Fonseca a propósito da noção de necessário (Delta 5) estão mais determinadas pela problemática teológica cristã do que pelo texto aristotélico tal como acontece no texto de 1592 do Curso Conimbricense. Haveria que explorar, neste contexto, uma ampla e rica problemática que todos os filósofos das religiões do Livro partilham. Agostinho, Ibn Sina, Ibn Rushd, Tomás de Aquino, Escoto, o autor do Liber de Causis, entre muitos outros, procuram reconciliar, cada um a seu modo, os essenciais da fé com aquilo que pensam ser a melhor doutrina filosófica. Para além de muitos outros aspectos que não poderemos sequer mencionar tem especial impacto nestas questões aquilo que, em cada caso, a teologia diz ao crente sobre a criação do mundo ex nihilo e sobre a concepção de Deus e seus atributos (a omnipotência, por exemplo). É essa também a preocupação de Fonseca e do autor do Curso Conimbricense. Partilham estas questões de fundo que vão perdurar ainda pela filosofia moderna não só em autores cimeiros como em muitos outros mal conhecidos e que nem sequer constam dos dicionários e enciclopédias.

CURSO Conimbricense, In Physic. Arist. Lib. II, c. 7, q. 4, a. 2.

8 Ver, por exemplo, CURSO Conimbricense, In Physic. Arist. Lib. II, c. 7, q. 15, a. 2, p. 286: "Occurrendum erit proloquium Philosophorum affirmantium essentias non habere causam efficientem, intelligi de conexionibus essentialibus, qualis est inter hominem et animal particeps rationis, quae cum non sint aliud formaliter, quam relationes identitatum, fundamentaliter uero negationes diuersitatis, ut docte explicat Fonseca lib. 5. Metaphy. cap. 5, q. 1, sect. 4 nequeunt ab ulla causa effici". 
Quadro 1 - Mapa de questões sobre a causalidade

\begin{tabular}{|c|c|}
\hline Fonseca, 1577, 1589, 1604 & Curso Conimbricense, 1592 \\
\hline Met. A(I), 7 & Phys. II, cap. 7 \\
\hline Q. 1 - Quot sint causarum genera & $\begin{array}{l}\text { q. } 1 \text { - Utrum causa recte a philosophis } \\
\text { definiatur an non }\end{array}$ \\
\hline Met. A(II), 2 & \\
\hline $\begin{array}{l}\text { Q. } 1 \text { - Num eiusdem rei dari possint } \\
\text { infinitae causae }\end{array}$ & $\begin{array}{l}\text { q. } 2 \text { - Utrum ne causarum ge } \\
\text { quattuor sint an non? }\end{array}$ \\
\hline & q. 3 - Quidnam sit exemplar \\
\hline Metaph. $\Delta(\mathrm{V}), 1$ & $\begin{array}{l}\text { q. } 4 \text { - Utrum exemplar uere ac proprie } \\
\text { causa sit ad genus causae formalis }\end{array}$ \\
\hline Q. 7 - Num principium latius pateat & pertinens? \\
\hline quam causa & q. 5 - Sitne omnis causa effectu suo \\
\hline Metaph. $\Delta(\mathrm{V}), 2$ & nobilior? \\
\hline $\begin{array}{l}\text { Q. } 1 \text { - Quaenam sit ratio causandi } \\
\text { materiae }\end{array}$ & $\begin{array}{l}\text { q. } 6 \text { - In quonam causalitas seu } \\
\text { causandi ratio consistat. }\end{array}$ \\
\hline Q. 2 - Quae sit ratio causandi formae & $\begin{array}{l}\text { q. } 7 \text { - Quae sit ratio causandi } \\
\text { efficientis causae }\end{array}$ \\
\hline $\begin{array}{l}\text { Q. } 3 \text { - Num materia in suo esse } \\
\text { pendeat a forma et uicissim forma a } \\
\text { materia }\end{array}$ & $\begin{array}{l}\text { q. } 8 \text { - Utrum singulae causae } \\
\text { peculiares sibi causalitates uendicent, } \\
\text { an non. }\end{array}$ \\
\hline $\begin{array}{l}\text { Q. } 4 \text { - Quid sit, formam educi e } \\
\text { potentia materiae }\end{array}$ & $\begin{array}{l}\text { q. } 9 \text { - Utrum causae sibi mutuo } \\
\text { causae sint, an non? }\end{array}$ \\
\hline $\begin{array}{l}\text { Q. } 5 \text { - Quaenam sit ratio causandi } \\
\text { efficientis causae }\end{array}$ & $\begin{array}{l}\text { q. } 10 \text { - Utrum Deus res omnes in suo } \\
\text { esse conseruet, an non? }\end{array}$ \\
\hline $\begin{array}{l}\text { Q. } 6 \text { - Num accidentalis forma } \\
\text { attingat productionem substantiae }\end{array}$ & $\begin{array}{l}\text { q. } 11 \text { - Utrum causae secundae re uera } \\
\text { aliquid agant, an non? }\end{array}$ \\
\hline $\begin{array}{l}\text { Q. } 7 \text { - Num res aliae infra Deum } \\
\text { aliquid agant }\end{array}$ & $\begin{array}{l}\text { q. } 12 \text { - Utrum Deus cum causis } \\
\text { secundis ad quemlibet earum actionem }\end{array}$ \\
\hline $\begin{array}{l}\text { Q. } 8 \text { - Num res creatae tantam agendi } \\
\text { uim habeant ut creare possint }\end{array}$ & eliciendam actu concurrat? \\
\hline $\begin{array}{l}\text { uim habeant ut creare possint } \\
\text { Q. } 9 \text { - Num res creatae agant } \\
\text { aut agere possint non concurrente }\end{array}$ & $\begin{array}{l}\text { q. } 13 \text { - Utrum ne Deus aliqua praeuia } \\
\text { motione causas secundas ad agendum } \\
\text { excitat? }\end{array}$ \\
\hline $\begin{array}{l}\text { immediate ad actionem primo agente } \\
\text { O. } 10 \text { - Quaenam sit ratio causandi } \\
\text { finalis causae }\end{array}$ & $\begin{array}{l}\text { q. } 14 \text { - Utrum Deus immediatione } \\
\text { uirtutis et suppositi cum omni agente } \\
\text { cerato operetur. }\end{array}$ \\
\hline $\begin{array}{l}\text { Q. } 11 \text { - Num finis sit causa secundum } \\
\text { esse intentionale, quod uocant, na uero } \\
\text { secundum esse reale }\end{array}$ & $\begin{array}{l}\text { q. } 15 \text { - Utrum causa prima actionem } \\
\text { secundae, an secunda actionem primae } \\
\text { determinet? }\end{array}$ \\
\hline $\begin{array}{l}\text { Q. } 12 \text { - Num omnes causae secundae, } \\
\text { cuiuscumque sit generis, Deo } \\
\text { essentialiter subordintae sint }\end{array}$ & $\begin{array}{l}\text { q. } 16 \text { - Utrum ne recte concedatur, } \\
\text { aliquid esse, quod diuina potentia fieri } \\
\text { non possit? }\end{array}$ \\
\hline
\end{tabular}




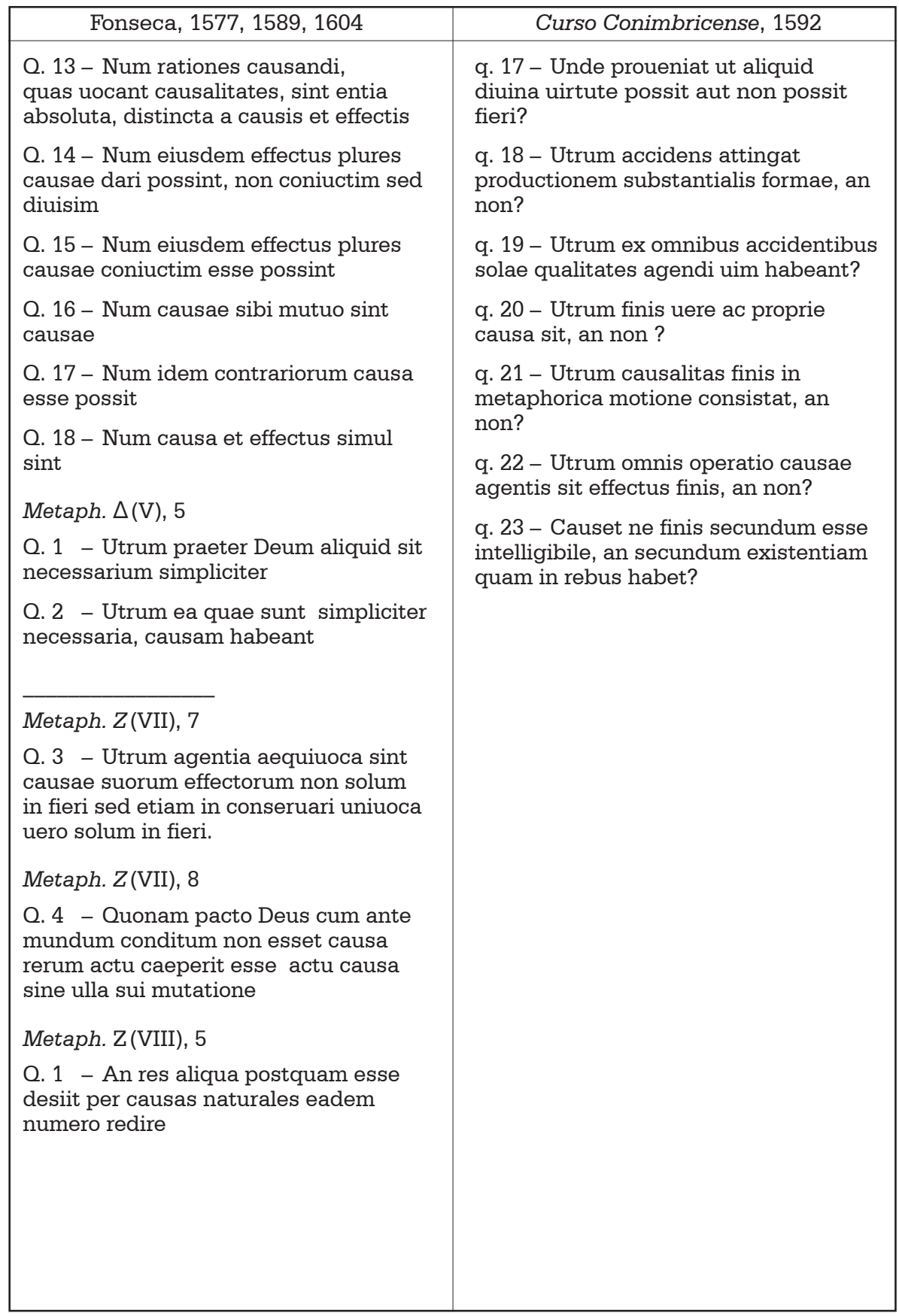


Sobre a noção de causa, diz-nos Fonseca que, em boa verdade, nem Aristóteles nem qualquer outro filósofo grego definiram o que é uma causa:

Et quidem quid causa sit, nec ab Aristotele usquam Nec ab alio Graecorum (quod sciam) in commune expositum est, ut uidere licet in enarrationibus tertii capitis 2 libr. Physic. \& secundi capitis libri quinti huius operis. ${ }^{9}$

Continua dizendo que é costume apresentar uma definição alegadamente retirada do Liber de Causis que é apresentada em duas versões: Definição 1: "causa est id ad quod aliud sequitur"; definição 2: "[causa est ] id ad cuius esse aliquid sequitur". Fonseca considera equivalentes estas definições declarando: 1) que não servem como definição de causa e 2) que nenhuma destas definições se encontra no Liber de causis. ${ }^{10}$ Este escrito, durante muito tempo atribuído a Aristóteles, influenciou profundamente o modo como durante a Idade Média os pensadores cristãos e muçulmanos articularam a dependência causal do mundo relativamente à causa primeira. Fonseca tem perfeita noção de que se trata de uma obra espúria. Mas o mais importante é que nem a definição apresentada como sendo proveniente dessa obra explica suficientemente a noção de causa nem encontra nela outra definição de causa que possa aceitar. ${ }^{11}$ Fonseca acaba por optar por outra definição que se aplique a todo o tipo de causas e que permita distinguir claramente a causa do efeito. Assim, define causa como "id, a quo aliquid per se pendet". ${ }^{12}$ Para além de lhe permitir evitar qualquer confusão entre causa e efeito, esta definição servirá também a Fonseca para tomar posição face a certas discussões teológicas negando qualquer dependência causal no interior da trindade. Esclarece ainda que o termo "causa" se pode usar de três modos: em sentido absoluto, relativo e de dependência:

Illud tamen animaduertendum est, tribus modis posse causam accipi. Uno pro re, quae denominatur causa, omnino tamen absolute accepta, ut pro sole, aut homine. Altero, relatiue, hoc est, quatenus significat relationem ad effectum, quo pacto est simul natura cum effectu. Tertio, quatenus ab ea pendet effectus, qui modus medius est inter duos traditos; atque hoc pacto non dubium est quin causa sit prior effectu. ${ }^{13}$

9 PEDRO da Fonseca. CMA I, c. 7, q. 1, s. 3, 315.

10 PEDRO da Fonseca. loc. cit.: "Quanquam uero utraque definitio idem ualet, neutra tamen in libro citato legitur aut satis uidetur rem declarare".

11 Pensa-se hoje que o autor anónimo do Liber de causis terá escrito este texto em árabe cerca de 950, a tradução latina de Gerardo de Cremona (ca 1170) foi editada por A. Pattin, 1966 (Lovaina) e está acessível em formato digital nos sítios da Bibliotheca Augustana e das colecções Intra Text.

12 PEDRO da Fonseca. CMA I, c. 7, q. 1, s. 3, 316.

13 PEDRO da Fonseca. CMA I, c. 7, q. 1, s. 3, 316-317. 
Conclui esta secção dizendo que o terceiro uso representa o ponto de vista mais característico da análise do filósofo e remete para a análise da ratio causandi ou como Fonseca diz também usando a terminologia da escolástica que lhe está mais próxima, das causalitates, precisamente no tratado das causas (Fonseca, 1589). O que nos apraz salientar não é tanto a escolha desta definição que não anda muito longe de outras discutidas pelos seus contemporâneos mas a perspicácia com que nota que nem Platão nem Aristóteles ou qualquer outro Grego definiram o conceito de causa. Ainda hoje se discute muito na literatura especializada sobre a origem e o verdadeiro sentido deste conceito e dos termos aitia, aition. ${ }^{14}$ Muitos intérpretes crêem que a investigação de Aristóteles sobre as causas está numa linha de continuidade com a iniciada por Platão em Fédon (62a-102a). Carlo Natali, partindo de uma análise das causas no Timeu, faz um confronto com a doutrina aristotélica das quatro causas concluindo que se trata de dois quadros teóricos muito diferentes. Natali interpreta aitia em Platão como significando primordialmente algo que

14 FREDE (1980) interrogava-se sobre o sentido da "noção original de causa" defendendo a tese de que no Fédon de Platão aitia era usado para falar de itens proposicionais enquanto que aition se referia a itens não proposicionais. Continuando a ser citado até hoje como um artigo seminal o certo é que não se gerou qualquer consenso nesta matéria. SEDLEY (1998) propôs-se analisar a relação causa-efeito no Fédon defendo uma interpretação segundo a qual as causas seriam coisas (e não eventos, estados de coisas ou algo de semelhante). Aition seria "thing responsible", na linha das analogias da esfera jurídica. Porém, LEDBETTER (1999) apresentou argumentos bastante convincentes para rejeitar a interpretação de Frede. A distinção entre aitia e aition seria usada por Platão de forma bastante consistente ao longo de todo o Corpus Platonicum mas não no sentido proposto por Frede. LEDBETTER (1999, p. 258-9) defende que Platão usa de preferência aitia para significar razão; aition, pelo contrário, estaria mais frequentemente associado à noção de causa ou explicação causal. Mas, aquilo que parecia ser um avanço real na investigação cedo se revelou igualmente problemático. WOLFSDORF (2005) reexaminou todas as ocorrências de aitia, aition e aitios no Corpus Platonicum, excluindo, numa segunda releitura, as ocorrências de aitia e aition no Fédon (para evitar a circularidade da argumentação) e, numa fase posterior, todas as ocorrências de aitia no sentido estritamente legal. Destas exclusões resultou um total de 242 ocorrências cuja frequência se distribuiria da seguinte forma: o adjectivo aitios ocorre 105 vezes, o nome aitia 90 vezes e o nome aition ocorre 47 vezes. A análise dos passos em que surgem estas ocorrências permitiu a WOLFSDORF (2005, p. 342) concluir que também a interpretação de Ledbetter é insustentável e que Platão não faz qualquer distinção semântica significativa no uso dos nomes aitia e aition. Esta conclusão de Wolfsdorf parecenos mais compatível com a letra dos textos mas deixa-nos com os problemas já conhecidos da interpretação do texto platónico. Também neste caso os resultados dependem muito do nível e profundidade da análise que se quiser e puder levar a cabo. HANKINSON (1998) investiga a problemática das causas num contexto mais amplo que vai de Tales aos neoplatónicos mas não traz novidade significativa na interpretação de Platão e Aristóteles e é particularmente insatisfatório no que diz respeito ao neoplatonismo. 
produz um efeito enquanto para Aristóteles a causa seria um princípio. ${ }^{15}$ Isto leva-nos a considerar a interpretação que Fonseca faz desta relação entre causa e princípio em Aristóteles.

\section{III}

Fonseca reconhece que Alguns textos de Aristóteles podem ser interpretados no sentido de uma equivalência entre causa e princípio. Contudo, chama a atenção para a necessidade de estarmos atentos à diferença entre um uso corrente de aitia (populari acceptione) e um uso filosófico, mais específico. Num uso corrente (popular) aitia designaria não só aquilo que é causa em sentido restrito como também a ocasião, as condições sine quibus non, e outras coisas vulgarmente associadas à ocorrência de algo:

Sumitur enim quatenus complectitur ea quae requiruntur, licet non sint uerae cuasae: quo pacto occasio, conditiones sine quibus non, et alia pleraque uulgo dicuntur causae. Hoc autem modo ne ipsa quidam priuatio formae introducenda a nomine causae interdum excluditur, ut apud eundem 12 lib. huius operis, c. $2 .^{16}$

Em sentido mais técnico, filosófico, dirá Fonseca que os dois termos não são equivalentes nem intersubstituíveis. Mesmo que se interprete Aristóteles no sentido de se poder dizer que todas as causas são princípios não se deve nunca confundir estes dois termo ${ }^{17}$ pela simples razão de que nem todos os princípios são causas. Fonseca sintetiza a sua posição sobre esta matéria apontando cinco argumentos para justificar a diferença entre causa e princípio. Em primeiro lugar, toda a verdadeira causa é um ente bem como o causado não se podendo dizer o mesmo de todos os princípios. ${ }^{18} \mathrm{Em}$ segundo lugar, a causa é sempre algo numericamente diferente do efeito não se passando o mesmo com todos os princípios. ${ }^{19}$ Em terceiro lugar, porque as causas comunicam àquilo de que são causas alguma entidade. Isto não acontece nos princípios como se pode

15 Cf. NATALI. 2005

16 PEDRO da Fonseca. CMA II, c.1, q. 7, s. 2, 53.

17 PEDRO da Fonseca. CMA II, c.1, q. 7, s. 2, 54.

18 PEDRO da Fonseca. CMA II, c.1, q. 7, s. 1, 51: "Principium et causam hoc primum differunt inter se, quod omnis vera causa est ens, quemadmodum et omne id quod est uere causatum: non omne autem principium est ens, quemadmodum neque omne principiatum, ut patet in priuatione et in saptio extra coelum."

19 PEDRO da Fonseca. CMA II, c.1, q. 7, s. 1, 51-52: "Differunt deinde quod sempre causa est aliud ab effectu, hoc est, essentiae diuersae numero, principium autem non necessario est diuersae numero essentiae $a b$ eo cuius est principium, potest enim esse uel eiusdem numero essentiae, ut in diuinis personis, uel saltem non diuersae ut in iis principiis quae non habent rationem entis." 
ver claramente, sublinha Fonseca, nos casos da privação da forma e da própria geração. ${ }^{20} \mathrm{O}$ quarto argumento aprofunda o anterior afirmando uma relação de dependência do causado relativamente à causa que iria para além do simples habere esse ab illo, dependência esta que não se verificaria sempre no caso dos princípios. ${ }^{21}$ Finalmente, o argumento de que a causa é, por natureza, anterior ao seu efeito, prioridade esta que não se verifica em todos os princípios. ${ }^{22}$ Fonseca conclui pela reafirmação inequívoca da tese segundo a qual princípio e causa não se podem confundir pois o termo princípio é usado num sentido muito mais amplo que o de causa. Esta é também a opinião dos que ele tem na conta de melhores intérpretes de Aristóteles: Alexandre, Alberto Magno, Tomás de Aquino e Averróis. ${ }^{23}$

\section{IV}

Considerando, portanto, causa no seu uso mais técnico poderemos analisar, com Fonseca, a doutrina das quatro causas. Relativamente à doutrina aristotélica das causas encontramos as posições mais díspares hoje. Por um lado ela é ignorada ou, o que vai a dar no mesmo, já sobejamente conhecida mesmo por quem nunca leu uma linha de Aristóteles. Entre aqueles que se queixam do esquecimento do contributo de Aristóteles, citemos, por exemplo, Anna Marmodoro ${ }^{24}$ que diz ser surpreendente o facto de a análise aristotélica não ser sequer reconhecida como um capítulo na longa história da análise da causalidade. Centrando a sua análise no texto de Phys. III. 3, Marmodoro ${ }^{25}$ procura explicar as relações metafísicas que Aristóteles usa no seu modelo de explicação causal. Diz-nos também que a esmagadora maioria dos comentadores, desde a Antiguidade até aos contemporâneos, passado pelos medievais, não fizeram esta análise porque interpretaram este texto de Aristóteles como se apresentasse

20 PEDRO da Fonseca. CMA II, c. 1, q. 7, s. 1, 52: "Differunt tertio, quod ab omni causa habet aliquod esse id cuius est causa: non item ab omni principio, id cuius est principium: quod idem patet in priuatione formae et in generatione ipsa, cuius priuatio est principium; priuatio enim, ut nullum esse habet, ita nullum dare potest".

21 PEDRO da Fonseca. CMA II, c. 1, q. 7, s. 1, 52: "Differunt quarto, quod ab omni causa pendet modo aliquo in suo esse, id cuius est causa (quod plus est quam habere esse ab illo) non item ab omni principio id cuius est principium, quod in superioribus exemplis cerni potest".

22 PEDRO da Fonseca. CMA II, c. 1, q. 7, s. 1, 52: "Postremo (mittamus enim alia si quae sunt discrimina) quod omnis causa est prior natura suo effectu: non item omne principium eo cuius est principium, quod etiam patet in personis diuinis producente et producta, in priuatione formae ac generatione et aliis plerisque".

23 PEDRO da Fonseca. CMA II, c. 1, q. 7, s. 1, 52.

24 Cf. MARMODORO. 2007, p. 205.

25 Cf. MARMODORO. 2007, p. 207 
duas descrições da mesma coisa. ${ }^{26}$ Marmodoro (2007) tem razão ao lamentar o facto de grande parte da vasta literatura mais recente sobre a causalidade, produzida por filósofos, ignorar Aristóteles (bem como toda a tradição filosófica anterior a Hume) ${ }^{27}$ Por outro lado, no âmbito da literatura mais especializada, produzida pelos ancient philosophers, não faltou quem pusesse em causa a interpretação tradicional da doutrina das causas em Aristóteles no âmbito das investigações sobre causalidade e determinismo na Filosofia Grega Antiga. Alguns intérpretes foram mesmo ao ponto de afirmar que Aristóteles teria defendido uma posição determinista. Stefano Maso e Carlo Natali editaram uma importante colectânea de estudos onde se faz o ponto da situação corrigindo os erros postos a descoberto pela investigação mais recente mas reabilitando as grandes linhas da interpretação tradicional da controvérsia sobre causalidade e determinismo. ${ }^{28}$

Fonseca faz uma abordagem dialéctica alinhando as diversas posições quanto ao número de causas e sua configuração. Conhecia, com certeza, os principais textos sobre esta matéria, antigos, medievais e seus contemporâneos. A alguns cita apenas pelo nome (Empédocles, Anaxágoras, Platão, Aristóteles, Cícero, Séneca, Alexandre de Afrodísia, Agostinho, Avicena, Tomás de Aquino, Henrique de Gand, Escoto, Caietano) ${ }^{29}$ ou de forma genérica (estóicos, escolásticos, antigos filósofos da natureza). Cita, de preferência, os textos de Platão (Fédon, Hipias Maior, Timeu) e sobretudo de Aristóteles, como seria de esperar. Para caracterizar a doutrina do estoicismo, apoia-se em Séneca e em Diógenes Laércio.

Para discutir a justeza do esquema quadripartido de Aristóteles começa a sua análise dialéctica elencando as opiniões daqueles que dizem haver menos causas (só uma causa, ou duas ou três) e dos que defendem haver mais causas do que as quatro indicadas por Aristóteles.

${ }^{26}$ MARMODORO. 2007, p. 207: "But the textual evidence supports, in my view, the introduction of two natures, not descriptions, out of which the causal interaction is built".

27 Mesmo a filosofia posterior a Hume raramente é tida em conta. De Hume passa-se, eventualmente, por Stuart Mill para entrar logo na discussão do séc. XX. Neste caso, uma das principais omissões é a da doutina kantiana da causalidade.

28 Cf. MASO; NATALI. 2005.

29 A citação mais longa que se faz nesta quaestio é da célebre Carta 65 de Séneca que Fonseca usa não só como testemunho da posição alegadamente defendida por alguns platónicos de que haveria cinco causas (as quatro de Aristóteles mais a exemplar) mas também como fonte das teses próprias do estoicismo. Não podemos analisar aqui estes textos nem discutir a problemática complexa que os envolve. Para uma apreciação crítica deste texto de Séneca ver a edição de Inwood com comentário a esta carta 65: SENECA. 2007, p. 136-148. Salvo melhor opinião, a leitura de Inwood confirma o acerto da leitura de Fonseca. 
Aqui a discussão passa necessariamente por saber se existe e em que consiste a chamada causalidade exemplar. Para Fonseca, com efeito, a causalidade exemplar não constitui um quinto modo a acrescentar às quatro causas de Aristóteles pois ela é, de facto, redutível a uma dessas quatro causas. Mas Fonseca não aceita a interpretação daqueles que a pretendem reduzir à final ou à eficiente. Nem Alexandre, nem os estóicos nem Escoto estão com a razão. Seria, antes, redutível à causa formal. ${ }^{30}$ Aos que contestam esta posição pelo facto de a causa formal, em sentido aristotélico, ser uma causa interna e o modelo (exemplar) ser sempre exterior Fonseca responde que, tomadas as quatro causas in commune não há qualquer razão para multiplicar o número de causas. $O$ que se diz em geral, aplica-se também ao caso da forma. ${ }^{31}$ A justificação sumária do esquema aristotélico da causalidade segue uma estratégia descritiva. De todos os efeitos conhecidos não se conhece nenhum que não precise destas quatro causas para sua explicação cabal e também não se conhece nenhum que precise de mais algum além destes quatro tipos de causalidade. ${ }^{32}$ Por outro lado, a completude do esquema causal resulta da própria definição de cada um dos tipos de causa a partir do modo como Aristóteles os introduziu na Física e na Metafísica. ${ }^{33}$ Fonseca está aqui, porventura, a mostrar-se excessivamente confiante neste tipo de descrições fenomenológicas e na capacidade de eliminar os equívocos através de uma técnica apurada de distinções.

Finalmente, duas palavras sobre o lugar sistemático da análise da causalidade. Fonseca sabe perfeitamente que Aristóteles tratou destas matérias nos livros da Física e nos escritos da Metafísica, em V, 2, por exemplo, reproduz mesmo textualmente a análise da Física. Fonseca justifica este facto dizendo que talvez Aristóteles ainda não tivesse desenvolvido plenamente a sua doutrina metafísica quando redigiu este texto. Fonseca não pretende negar o uso universal que se faz das causas em múltiplas formas de saber. E não desconhece que foi no âmbito da

30 PEDRO da Fonseca. CMA I, lib. I, c. 7, q. 1, s. 5, 321-324. Invoca Tomás de Aquino e Caietano como defensores de posição semelhante.

31 PEDRO da Fonseca. CMA I, lib. I, c. 7, q. 1, s. 5, 325: "Quod si quis urgeat, cum exemplaris causa sit directo et non reductitie causa formalis, adhuc effici ex dictis quinque esse causarum genera, finalem, efficientem, exemplarem, formalem internam et materialem; occurrendum est, si genera causarum sumantur in commune, non esse nisi quatuor, cum exemplaris et formalis interna, sub formali contineantur".

32 PEDRO da Fonseca. CMA I, lib. I, c. 7, q. 1, s. 4, 317.

33 PEDRO da Fonseca. CMA I, lib. I, c. 7, q. 1, s. 4, 318: "Idem quoque licet ostendere ex definitionibus materiae, formae, efficientis et finis, adhibitis argumentis iis quibus Arist. ad eandem conclusionem probandam utitur. Quod enim haec quatuor sint verae ac proprie causae, ex descriptione causae, expensis singularum definitionibus perspicuum erit". 
física, em sentido antigo, que surgiu a doutrina das causas. Porém, defende a tese de que não é o lógico nem o físico mas sim o metafísico quem deve tratar das causas enquanto tais e não enquanto causas do movimento na natureza ou enquanto termo médio de uma demonstração. Em primeiro lugar, porque causa e efeito, assim considerados, são algo que transcende os objectos de todas as ciências particulares. ${ }^{34}$ Tratar das causas enquanto causas do movimento e do devir é algo que Fonseca reconhece ser do domínio da Física ${ }^{35}$ e a outros domínios do saber pertencerá falar das causas dentro da esfera da sua respectiva competência. Mas para além de reconhecer, na linha de Aristóteles, autonomia aos diversos saberes, Fonseca reclama um estatuto especial para o saber do metafísico que aqui não poderemos analisar em pormenor mas poderia, porventura, revelar-se mais actual do que parece à primeira vista. Numa visão arquitectónica do saber, o metafísico é caracterizado como aquele que tem por tarefa fazer a articulação universal das causas de todas as coisas, tanto quanto o engenho humano e a arte o permitirem. $^{36}$

\section{Referências}

BERTI, E. Nuovi studi aristotelici. II. Brecia: Morcelliana, 2005.

"Unmoved mover(s) as efficient cause(s) in Metaph. XII 6". In: FREDE, M.; CHARLES, D. (eds.). Aristotle's Metaphysics Lambda. Symposium Aristotelicum. Oxford: Clarendon, 2000, p. 181-206.

CARRAUD, V. Causa sive ratio. La raison de la cause, de Suarez a Leibniz. Paris: PUF, 2002.

COMMENTARII Colegii Conimbricensis S. J. In Octo Libros Physicorum Aristotelis Stagiritae. Coimbra: A Mariz 1592.

FREDE, M. "The Original Notion of Cause". In: BARNES, BUMYEAT, SCHOFIELD (eds.). Doubt and Dogmatism. Oxford: Oxford University Press, 1980, p. 217-249.

34 PEDRO da Fonseca. CMA I, lib. I, c. 7, q. 1, s. 2, 313: "Dicendum est tamen, prorium reuera esse Metaphysici de causis, ut causae sunt, agere, neque id ad alium artificem spectare. Primum, quia causa et effectus sunt primae et adequatae differentiae entis, de primis autem eiusmodi differentiis, non dubium est quin solus Metaphysicus agere possit; transcendit enim hoc genus diuisionum entis subiecta omnia caeterarum scientiarum".

35 PEDRO da Fonseca. CMA I, lib. I, c. 7, q. 1, s. 2, 314: "Dixi de causis, ut causae sunt, quia de causis, ut sunt coniunctae cum motu, aut sub alia speciali ratione pertinente ad subiectum alicuius particularis scientiae, non dubium est quin eadem ipsa particularis scientia agere posse ac debeat. Atque haec est communis Philosophorum sententia".

36 PEDRO da Fonseca. CMA I, lib. I, c. 7, q. 1, s. 2, 315: "Iam illud, quod res Physicae plures causas sibi vendicant quam Metaphysicae, nihil est ad rem. Metaphysicus enim cum sit primus artifex, et communis omnium scientiarum, ut ita dicam architectus, non tantum de causis rerum materiae expertium, sed omnium omnino rerum, quoad eius dignitas et officium permittit, agere debet". 
HANKINSON, R. I. Cause and Explanation in Ancient Greek Thought. Oxford: Oxford University Press, 1998.

LEDBETTER, G. M. "Reasons and Causes in Plato: The Distinction between aitia and aition". Ancient Philosophy 19 (1999), p. 255-265.

MARMODORO, A. "The union of cause and effect in Aristotle: Phys. 3.3". Oxford Studies in Ancient Philosophy 32 (2007), p. 205-232.

MARTINS, A. M. "A metafísica inacabada de Pedro da Fonseca". Revista Portuguesa de Filosofia XLVII (1991), p. 517-533.

MASO, S.; NATALI, C. (a cura di). La catena delle cause. Determinismo e antideterminismo nel pensiero antico e contemporaneo. Amsterdam: Hakkert, 2005.

NATALI, C. "Les causes du Timée et la théorie des quatre causes". In: FATTAL, M. La philosophie de Platon. Tome 2, volume 2, Paris: L'Harmattan, 2005, p. 347-356 [Trad. francesa do original publicado em italiano in: CALVO, T.; BRISSON, T. Interpreting the Timaeus-Critias, Sankt Augustin 1997, p. 207-216].

PEDRO da Fonseca. Commentariorvm... in libros metaphysicorvm Aristotelis... T. 1: Continet hic tomus quatuor primorum librorum explicationem.(Romae: Franciscus Zanettus \& Bartholomaeus Tosius, 1577); T. 2: Continet hic tomus quinti libri explicationem (Romae: Jacobi Tornerii \& Franciscus Zanettus, 1589); T. 3: Continet hic tomus 6. 7. 8. et 9. lib. Explicationem (Eborae: E. de Lyra, 1604); T.4: in metaphysicorum Aristotelis Stagiritae decimum, undecimum, \& duodecimum: cum sequentium duorum interpretatione (Lugduni: H. Cardon, 1612).

SEDLEY, D. "Platonic Causes". Phronesis 43 (1998), p. 114-132.

SENECA. Selected Philosophical Letters. Translated with Introduction and Commentary by Brad Inwood. Oxford: Clarendon, 2007, p. 136-148.

WOLFSDORF, D. "Aitiov and Aitia in Plato". Ancient Philosophy 25 (2005), p. 341348. 